\title{
Effect of Thermal Cycling and Open-Hole Size on Mechanical Properties of Polymer Matrix Composites
}

\author{
${ }^{\mathrm{a}}$ A.R. Ghasemi ${ }^{*},{ }^{\mathrm{a}}$ M. Moradi \\ ${ }^{a}$ Department of Solid Mechanics, Faculty of Mechanical Engineering, University of Kashan, 87317- \\ 51167, Kashan, Iran. \\ *Corresponding author: \\ Tel: (98) 31 55912426, \\ E-mail: Ghasemi@kashanu.ac.ir
}

\begin{abstract}
This paper investigates the effects of thermal cycling on mechanical degradation of polymer matrix composites (PMCs). Un-notched and open-hole specimens are tested using developed thermal cycling apparatus and tensile test machine. In addition, the hole-size effect of open-hole tension glass/epoxy composite laminates is investigated. The tensile strength, mass loss and surface degradation of the specimens were obtained during 250 cycles. Experimental results showed that the holes diameter is the main parameter to control the thermal cycling effects on open hole structure. Also, it is found that laminates with smaller holes have higher tensile strength variation than those with larger holes. The results showed that increment of the hole diameter and number of cycles decreases the tensile strength.
\end{abstract}

Keywords: Thermal Cycling, Mechanical Properties, Polymer Matrix Composite (PMC), OpenHole Specimens.

\section{Introduction}

Degradation of mechanical properties is one of the weaknesses of polymer matrix composites (PMCs) during thermal cycling. This weakness limits applications of this light and strength material in aerospace industry. During the past decades, different studies are done to identify thermal cycling effects on the PMCs specimens [1-2]. An earlier work in this area is done by Eselun et al. [3]. They found that resin micro cracks generated by thermal cycling affected gas permeability, fatigue life, tensile strength, modulus and interlaminar shear stresses. Also, the coefficient of thermal expansion (CTE) and coefficient of moisture expansion could change. 
They employed $[0 / \pm 60 / 0]$ and $[ \pm 30]$ tubes made from GY70 carbon-fiber and 934 epoxy resin. These samples were cycled six times between $248^{\circ} \mathrm{C}$ and -120 or $140^{\circ} \mathrm{C}$ at a rate of $3.68^{\circ} \mathrm{C} / \mathrm{min}$ and the performance monitored by X-rays, acoustic emission, mechanical testing and microscopy analyses. But the effects of the CTE in their results were not clear, because of the low number of thermal cycles and relatively low-temperature drop used.

An attempt to emulate the effect of a space environment on carbon/epoxy (T300/5208) specimens were made by Adams et al. [4]. Various symmetrical cross-ply laminates were used as $\left[0 / 90_{3}\right]_{\mathrm{s}},\left[0_{2} / 90_{2}\right]_{\mathrm{s}},\left[0_{3} / 90\right]_{\mathrm{s}},\left[90 / 0_{3}\right]_{\mathrm{s}},\left[90_{2} / 0_{2}\right]_{\mathrm{s}}$ and $\left[90_{3} / 0\right]_{\mathrm{s}}$ that were subjected up to 500 cycles between $-157^{\circ} \mathrm{C}$ and $121^{\circ} \mathrm{C}$ at a rate of $5.68^{\circ} \mathrm{C} / \mathrm{min}$. Transverse cracks were first detected at $46^{\circ} \mathrm{C}$ though many specimens remained crack free at the lowest temperature. In no case was crack saturation observed even after 500 cycles.

One of the important factors affecting in design of composite structures is the load carrying capability of the composite joints. Holes are intentionally created to reduce structural weight or to facilitate joining and access. However, hole also undergoes high stress concentration during loading, and consequently, damage is often initiated from the hole area. During flight, aircraft structure is certainly subjected to fatigue loading. If the structure is made of composite laminates and some parts are reinforced with stitching thread, it is imperative to investigate the fatigue characteristics of stitched laminates [5].

Recently, Ghasemi et al. [6-8] are used Taguchi method to consider a comprehensive experimental analyses to find main effective factors and fracture behavior of specimens on glass/epoxy composite components subjected to the thermal cycling. Statistical analysis of the experimental results showed that long splitting fiber breakage, lateral fiber breakage and angled breakage are dominate failure mode of the $[0]_{8},\left[0_{2} / 90_{2}\right]_{\mathrm{s}}$ and $[0 / \pm 45 / 90]_{\mathrm{s}}$ layups, respectively.

Also, different study is accomplished to consider the hole effects on mechanical properties of composites [9-11]. The effects of open hole on the strength and fatigue life of carbon/epoxy composite laminates have been studied [9]. Also, the tensile behavior of unidirectional glass fiber reinforced polymer laminates with drilled holes was investigated [10]. Salleh et al. reported the effect of drilled hole on the mechanical behavior of long kenaf composite with and without fiber glass reinforcement. The surface fracture, residual tensile strength and stiffness of natural fiber/ glass fiber hybrid composites were investigated. Since the drilling induced damage is 
inevitable, this article will provide useful information on the damage progression and its influence on the strength of hybrid kenaf/glass reinforced epoxy composites [11].

Shimokawa et al. [12] evaluated the effect of isothermal aging on the ultimate strength of composite materials. The hole-notched and un-notched panels, before being machined to specimens, were isothermally aged at $120^{\circ} \mathrm{C}$ and $180^{\circ} \mathrm{C}$ for up to 15,000 hours. Static tests at room and elevated temperatures before and after thermal aging provided the open-hole tensile, open-hole compressive and short beam shear strengths. Moreover, the effects of five oxidation resistant treatments on open-hole compressive strength at $180^{\circ} \mathrm{C}$ were investigated after isothermal aging of 5,000 hours at $180^{\circ} \mathrm{C}$. The test results clarified the effects of isothermal aging on ultimate strengths and oxidation resistant treatments on the open-hole compressive strength.

However, despite the extensive studies on mechanical behavior of open-hole laminates, authors found very limited publication on thermal cycling effects on the open hole laminated composite materials. Nakamura et al. [13] considered the thermal cycling tests up to 10,000 cycles on the two kinds of carbon fiber/thermoplastic-polyimide composite, and up to 1000 cycles on a carbon fiber/bismaleimide composite for use in the structures of the next-generation supersonic transport structures (SST). The laminates had a quasi-isotropic stacking sequence of 32 plies, (45/0/45/90) $)_{4 \mathrm{~S}}$. The open-hole compressive (OHC) specimens were short only in length in comparison test and the size of the hole was $6.35 \mathrm{~mm}$. The number of microcracks initiated was counted and the $\mathrm{OHC}$ strength investigated by static mechanical tests at room temperature before and after thermal cycling tests. The study discussed the relationship between the number of thermal cycles, number of microcracks initiated, and $\mathrm{OHC}$ strength. The results showed that the $\mathrm{OHC}$ strength before and after thermal cycles did not change. Therefore, thermal cycles and the initiation of transverse microcracks did not affect the OHC strength within their studies. However, this work did not present any data on the strength degradation variation of the laminates during thermal cycling loading.

There are no reports however dealing with the quantitative relationship between mechanical degradation by thermal cycling for different open-hole size polymer matrix composites. In this research, the hole-size effect of open-hole tension glass/epoxy composite laminates is investigated. Glass fiber and epoxy resin were used to prepare the required specimens. A twochamber apparatus and a tension test machine were used for thermal cycling and tension test on 
the specimens, respectively. Also, the tensile strength of glass/epoxy laminated composite materials was obtained using tensile test during 250 cycles. A correlation between the hole size and thermal cycles on the tensile strength was established. Then fracture analysis and surface degradation changes as a function of the hole diameter and the number of cycles are studied.

\section{Material and Experimental Conditions}

All tests and observations described in this paper were performed on glass/epoxy composites which used the ML506 epoxy resin and polyamine hardener (HA-11) as the matrix of composites. This resin has good mechanical properties and low viscosity that makes it a suitable material for the composite applications. Also, unidirectional E-glass fibers (supplied by Gurit ${ }^{\mathrm{TM}}$ ) have been used as the reinforcing material (Table 1). Laminates were prepared with $\left[0_{2} / 90_{2}\right]_{\mathrm{s}}$ stacking sequence. The composite laminates are fabricated using hand lay-up method and are allowed to cure for seven days at room temperature. The test specimens were cut from laminates according to the standard ASTM D3039 [14]. The fiber volume fraction of the composites was $53 \%$.

Three specimens were fabricated for each test. The specimens are in form of the rectangular cubic shape with $25 \pm 0.5 \mathrm{~mm}$ width. The thickness of each layer was $0.2 \mathrm{~mm}$ and the thickness of the specimens was $1.6 \pm 0.1 \mathrm{~mm}$ as shown in Fig. 1. The cross-ply glass/epoxy tabs were locally bonded on each side of the specimens. The size of the hole was 5 and $10 \mathrm{~mm}$ and also the unnotched specimens were considered to compare with the open hole results.

A thermal cycling apparatus consisting of heating and cooling chambers and a rail system for specimen motion was assembled to provide the temperature cycle of the specimens [6]. The thermal cycling tests consisted in 250 triangular thermal cycles, the maximum and minimum temperatures being, respectively of 100 and $0^{\circ} \mathrm{C}$ with constant cooling and heating rates of $17^{\circ} \mathrm{C} / \mathrm{min}$. Temperatures were measured with four thermocouple gauges; two sensors for measurement of the heating and cooling chamber temperature and two sensors for the two sides temperature of the specimens. An example of a temperature record is given in Fig. 2. The specimens were subjected to 0, 50, 100,150, 200 and 250 thermal cycles.

The mechanical tests were conducted on a $50 \mathrm{kN}$ hydraulic universal testing machine (Fig. 3), and each data point indicated in the results is an average of three separate specimens. Tensile tests are done on the proposed specimens with $2 \mathrm{~mm} / \mathrm{min}$ crosshead velocity. 


\section{Results and Discussion}

\subsection{Results of Tensile Test}

Three specimens groups were fabricated for each test. Tensile tests were performed on the specimens and the average results and standard deviations values (SDV) of the tensile tests are reported in Table 2. The tensile strengths of the laminates are measured using $S_{f}=\frac{F}{w t}$ that $\mathrm{F}$ is the maximum force, $w$ is the samples' width, and $t$ is the samples' thickness. All the open hole samples have been failed in the net tensile section due to the high stress concentration coefficient.

It is observed that the specimens with open-holes have the minimum tensile strength; while the un-notch specimens have the maximum results. As observed by the experiment, the strength reduction of the notched specimens was increased by increasing the hole diameter, as shown in Table 2. Also, it's cleared that tensile strength of the un-notched and the open hole specimens decreased 3-6\% after 250 cycles. The results show that the failure loads of the composite specimens are changed depending on the hole diameter during the thermal cycling.

The force-displacement curves of the layups under different thermal cycling conditions are provided in Fig. 4. The force-displacement curve in longitudinal direction was linear elastic until breakage. As shown in this figure, the hole diameter has significant effect on the behavior of force-displacement curves. Also, increment of the thermal cycling has been decreased the tensile strength in the un-notched specimens; while the open hole specimens show increment of the tensile strength after the thermal cycling. On the other hand, the specimens show the brittle behaviors and failure strain of specimens decreased after the thermal cycling.

\subsection{Fracture Behavior}

When the specimens specially the open hole specimens subjected to tensile test, cracks start to grow. These cracks initiate and grow on edge of the hole. Two long longitudinal cracks are visible (Fig. 5-a). When the cracks propagate to ultimate value, the composite samples will fractured. At the fracture moment, fiber and matrix particles split from the specimens and the specimen will break completely (Fig. 5-b). After breakage, lateral breakage and fiber splitting 
region could be seen in the specimen (Fig. 5-c). When failure occurs, material goes under property loss in the damaged region, and the extent of property reduction is related to the failure mode.

Study the failures regions of the composite specimens showed that the main characteristic parameter to change failure mode and region is the hole diameter (Fig. 6). As shown in this figure, different long fiber splitting is dominated failure mode of the un-notched specimens. At these specimens, long fiber splitting is extended in all regions. The open hole specimens show different failure behavior. For $\Phi=5 \mathrm{~mm}$, lateral breakage and fiber splitting along the hole edge are dominated failure modes. When hole diameter is $10 \mathrm{~mm}$, lateral breakage is dominated failure mode. Increment of the hole diameter caused to increase of failure region.

A smaller damage zone was observed in the larger holes, also damage pattern for larger holes were somehow different from the smaller ones. As shown in Fig. 6, the hole diameter changes failure modes of composite specimens; while thermal cycling changes failure regions without significant change in failure mode (Fig. 7).

As shown in Fig. 7, lateral breakage and fiber splitting is accrued at the un-notched specimens. Also, wide fiber-matrix debonding area is observed before thermal cycling. Thermal cycling decreased fiber-matrix deboning area and increased number of fiber splitting. Also, fiber splitting after thermal cycling is larger than unexposed specimens.

Same failure variation could be seen in the open hole specimens, too. For $5 \mathrm{~mm}$ and $10 \mathrm{~mm}$ hole diameter, fiber-matrix deboning area is decreased after thermal cycling. Also, fiber splitting of after thermal cycling is larger but limited than unexposed specimens. One reason of this increment can be increment of the oxidative reaction of the composite molecular components with the harsh environment. This mass and surface degradation in polymeric composites involves solid-gas reactions, and is associated with chain division cause to decrease of fibermatrix debonding. So, the load transfer of matrix will be decreased and stress will be concentrates on fibers region during thermal cycling.

Crack propagation during tensile test and thermal cycling is another interesting subject of fracture behavior study (Fig. 8-9). As shown in Fig. 8, in unexposed specimens cracks initiate and grow on the hole edges. Then the cracks propagate during test and reach to its ultimate length. Finally, ultimate crack distribution, lateral breakage and fiber splitting is accrued after 
tensile test. Also, same as unexposed specimens, cracks propagate in exposed specimens, but the crack region after thermal cycling is limited than unexposed specimens (Fig. 9).

\subsection{Multiple Linear Regression Models}

A multi variable polynomial curve fitting is used to establish the correlation between the number of cycles and hole diameter on tensile strength using MINITAB software [15] during thermal cycling. The regression function defined here is as follows:

$S_{f}(\omega, N)=A+B \omega+C N+D \omega N+E \omega^{2}+F N^{2}$

where $\mathrm{S}_{\mathrm{f}}$ is tensile strength, $\omega$ and $\mathrm{N}$ are holes diameter to width ratio and number of cycles, respectively. Also, A, B, C, D, E and F are the correlation coefficient that mentioned in Table 3.

\section{3-5 Sensitivity Analysis of Parameters}

The tensile strength behavior of the composite specimens under different thermal cycling conditions obtained using Eq.1. This model can be preparing a suitable tool to analyze the effects of the hole diameter and number of cycles on mechanical properties. For better study the combination of the factors, sensitivity analysis of these parameters is done and results are shown in Figs. 10-12.

As shown in Fig. 10, the tensile strength of un-notched specimen decreases linearly. Tensile strength reduction of this property is $6 \%$ after 250 cycles. In the open hole specimens, increment of the hole diameter caused to reduce the variation during thermal cycling. Consequently, the tensile strength for $\omega=0.63$ almost is constant. According to Saint-Venant's principle, stress in the vicinity of the large holes are subjected to very large stresses, while other element near the ends of the specimen are unaffected by the loading [16]. As mentioned in another works [17] the damage progression pattern in the hole with different diameter is different from the un-notched specimens. Stress concentration in the vicinity of the holes caused to instability behavior of specimens. This is the reason of reduction thermal cycling effect in comparison of the hole diameter effects on tensile strength.

For better comparison, the dimensionless tensile strength variation of each hole diameter is shown in Fig. 11. In this figure, $S_{\mathrm{f}}$ and $S_{\mathrm{f} 0}$ are the instant tensile strength and initial value of tensile strength, respectively. The variation of tensile strength in the open hole samples is so significant than the un-notched specimens. Also, when the hole diameters increases, instability of the results increase significantly. As shown in this figure, crack propagation in un-notched 
glass/epoxy composite caused to smooth decrease of tensile strength during thermal cycling. Behavior of the open hole is so different than the un-notched specimens. In these specimens, when the hole diameters increases, tensile strength increases significantly. It is seem that curing of the hole region of the glass/ epoxy composite during the thermal cycling caused to increase of this property.

Due to significant effect of hole diameter on tensile strength, sensitivity analysis of this parameter is done and considered in Fig. 12. As shown in Fig. 12, increment of hole diameter causes to decrease of tensile strength specially at high hole to width ratio. Also, it's found that degradation effects of thermal cycling in small $\Phi / \mathrm{W}$ ratio diameter are higher than the high ratio. This figure showed that hole in specimen cause significant stress concentration and instability of mechanical property variation in comparison with thermal cycling effects.

\section{Conclusion}

The behavior of the open hole glass/epoxy laminated composite materials subjected to thermal cycling is considered. A statistical approach was utilized to identify effects of thermal cycling and the hole diameter on tensile strength degradation of the composite specimens. The results showed that increment of thermal cycles decreases the tensile strength in un-notched specimens; while this variation in the open hole specimens is less than un-notched specimens. So, larger hole diameter shows less tensile strength variation. Sensitivity analysis of parameters showed that tensile strength of the specimens decrease between 3-6\% after 250 cycles. Also, increment of the hole diameter causes to decrease of tensile strength specially at high hole to width ratio.

Study the fracture behavior showed that, long fiber splitting is dominated failure mode of unnotched specimens. On the other hand, lateral breakage and fiber splitting along the hole edge are dominated failure modes of $\Phi=5 \mathrm{~mm}$ open hole. Also, lateral breakage is dominated failure mode of $10 \mathrm{~mm}$ hole diameter. These study showed that increment of the hole diameter caused to increase of failure region and failure mode changes. The observations showed that hole diameter changes failure modes of composite specimens; while thermal cycling changes only failure regions without significant change in failure mode. Moreover, thermal cycling decreases fibermatrix deboning area and increases number of fiber splitting, consequently. Due to surface oxidation and surface matrix degradation, fiber splitting after thermal cycling is larger than 
unexposed specimens. Hole in the specimen caused significant stress concentration and mechanical property instability in comparison with thermal cycling effects.

\section{Acknowledgments}

The authors are grateful to the University of Kashan for supporting this work by Grant No. $255980 / 10$.

\section{References}

[1] N.L Hancox. Thermal effects on polymer matrix composites: Part 1 Thermal cycling. Mater and Des 1998; 19:85-91.

[2] J.M Sousa, J.R Correia, S. Cabral-Fonseca, A.C Diogo. Effects of thermal cycles on the mechanical response of pultruded GFRP profiles used in civil engineering applications. Comp Struct $2014 ; 116: 720-731$.

[3] S.A Eselun, H.D Neubert, E.G Wolff. Microcracking Effects on Dimensional Stability. SAMPE Tech Symp 1979; 24:1229-1309.

[4] D.S Adams, D.E Bowles, C.T Herakovich. Thermally Induced Transverse Cracking in Graphite-Epoxy Cross-ply Laminates. J Reinf Plast \& Comp 1986; 3:152-169.

[5] A. Yudhanto, Y. Iwahori, N. Watanabe, H. Hoshi. Open Hole Fatigue Characteristics and Damage Growth of Stitched Plain Weave Carbon/Epoxy Laminates. Int J of Fatigue 2012; $43: 12-22$

[6] A.R. Ghasemi, M. Moradi. Low Thermal Cycling Effects on Mechanical Properties of Laminated Composite Materials. Mech of Mat 2016; 96:126-137.

[7] A.R. Ghasemi, M. Moradi. Surface Degradation of Polymeric Composite under Different Thermal Cycling Conditions. J Solid Mech 2016.

[8] A.R. Ghasemi, M. Moradi. An Experimental Investigation on Fracture Analysis of Polymer Matrix Composite Under Different Thermal Cycling Conditions. J Solid Mech 2016.

[9] E. Persson, I. Eriksson, L. Zackrisson. Effects of the Hole Machining Defects on Strength and Fatigue Life of Composite Laminates. Comp: Part A 1997; 28:141-51.

[10] V. Tagliaferri, G. Caprino, A. Diterlizzi. Effect of Drilling Parameters on the Finish and Mechanical Properties of GFRP Composites. Int J Mach Tool Manuf 1990; 30(1):77-84. 
[11] Z. Salleh, M.N. Berhan, K.M. Hyie, Y.M. Taib, A. Kalam, N.R.N Roselina. Open Hole Tensile Properties of Kenaf Composite and Kenaf/Fibreglass Hybrid Composite Laminates. Procedia Eng 2013; 68:399-404.

[12] T. Shimokawa, Y. Hamaguchi, Y. Kakuta, H. Katoh, T. Sanda, H. Mizuno, Y. Toi.

Effect of Isothermal Aging on Ultimate Strength of High Temperature Composite Materials for SST Structures. J of Comp Mater 1999; 33(12):1104-1118.

[13] H. Nakamura, R. Asagumo, H. Tamura, T. Shimokawa, H. Katoh, Y. Hamaguchi, Sh. Sanbongi, H. Mizuno. Effect of Thermal Cycling on Microcracking and Strength Degradation of High-Temperature Polymer Composite Materials for Use in Next-Generation SST Structures. J of Comp Mater 2002; 36:885.

[14] ASTM, D.D 3039M-95a, Standard test method for tensile properties of polymer matrix composite materials (1997).

[15] MINITAB 17 statistical software, Minitab Inc, 2013.

[16] F.P. Beer, R.R. Johnston, J.T. Dewolf, Mechanics of Materials. Fourth Edition, Page 106, 2006.

[17] F. Taheri-Behrooz, H. Bakhshan. Characteristic Length Determination of Notched Woven Composites. Adv Comp Mater 2016; 1:17. 


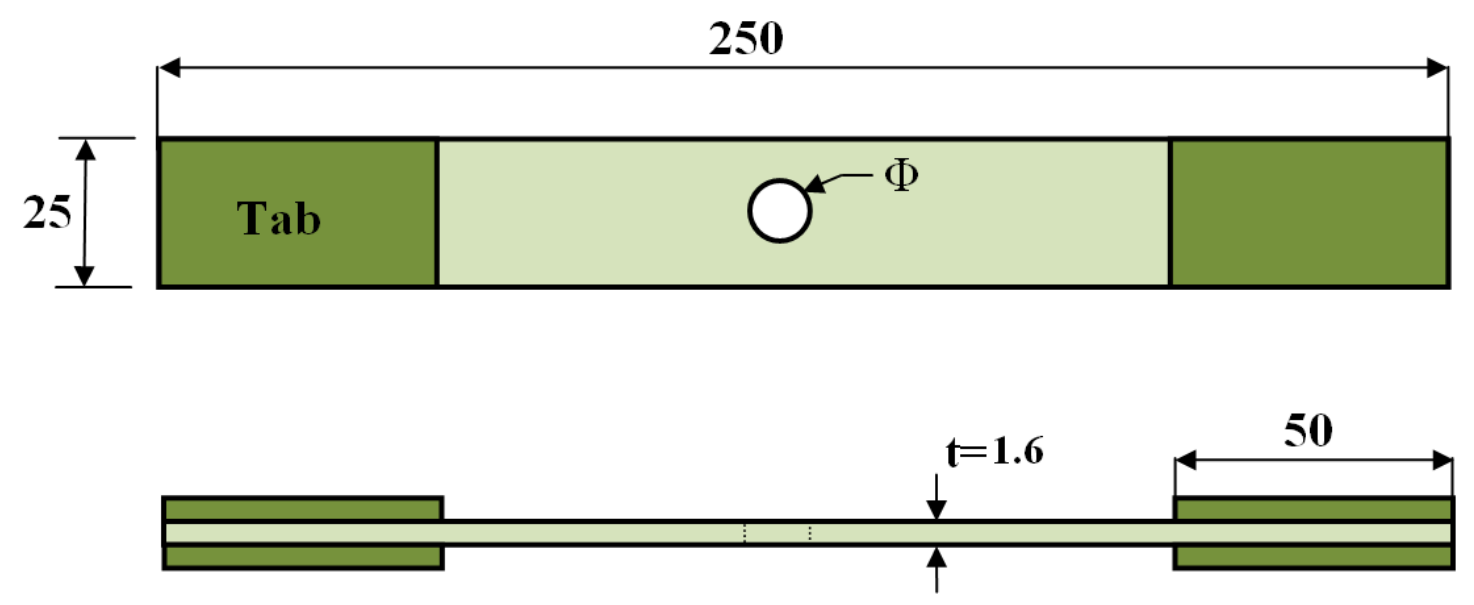

Fig. 1 tension test specimens with open hole

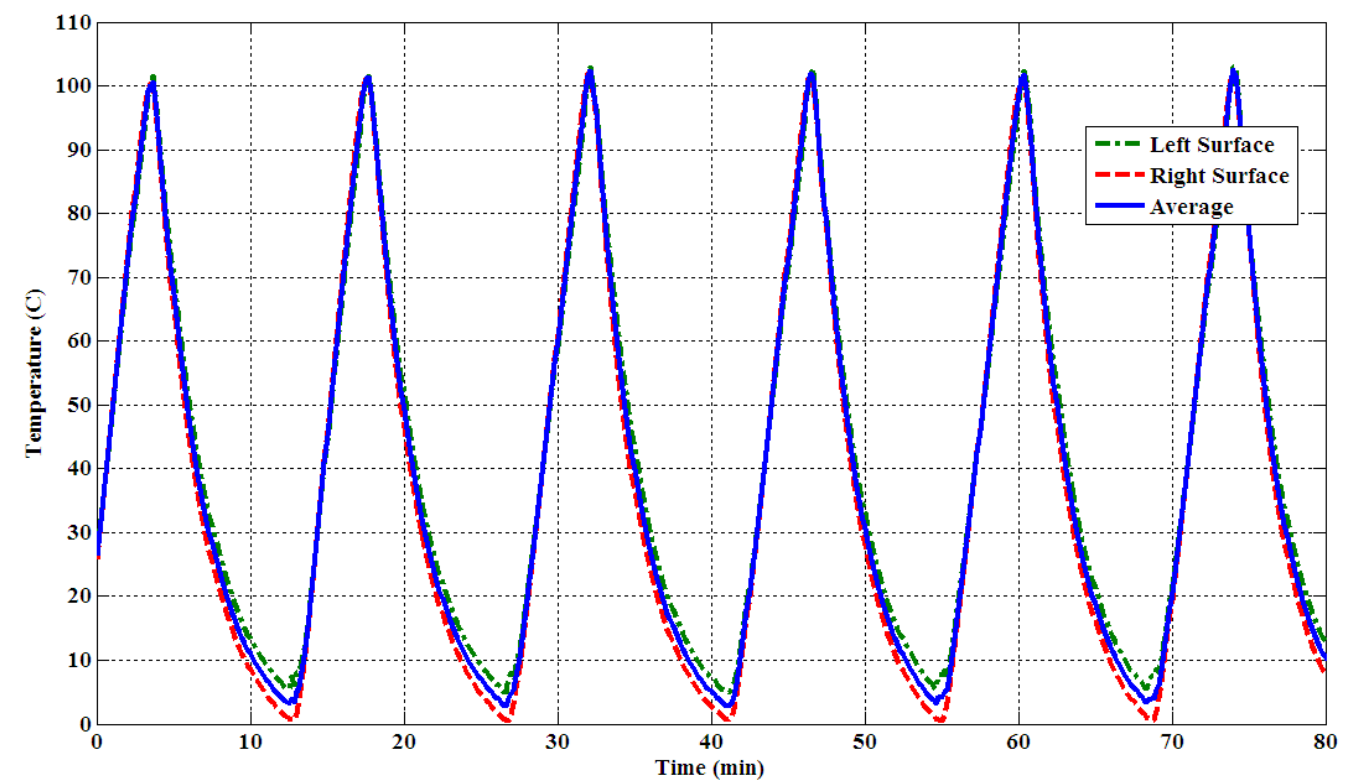

Fig. 2 Different experimental thermal cycling profile 

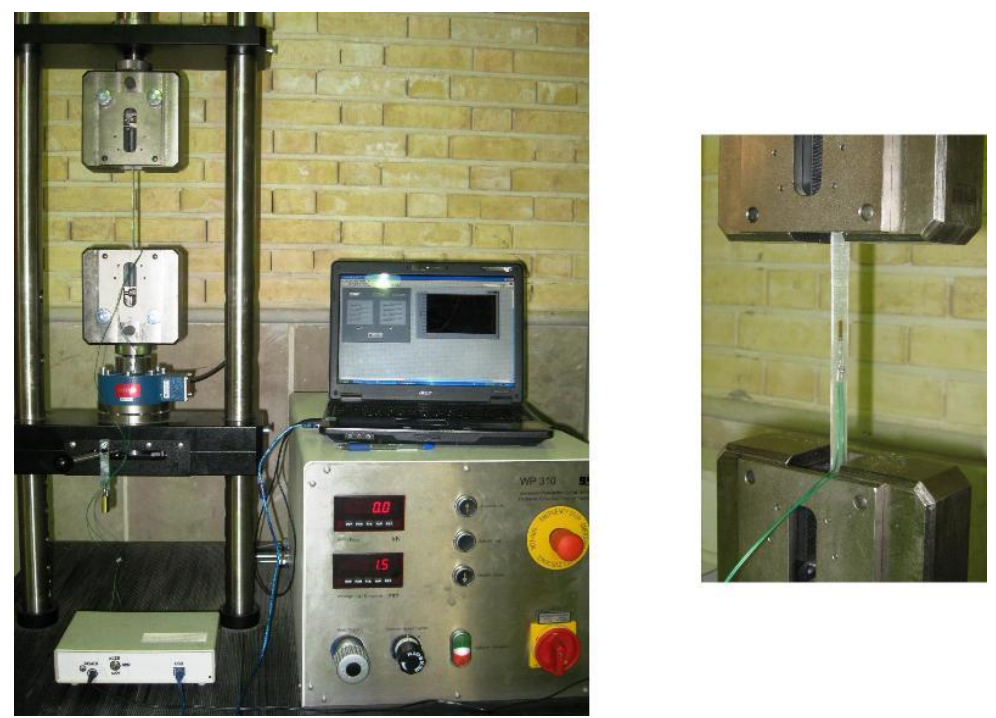

Fig. 3 Tensile test of the specimens using hydraulic universal testing machine

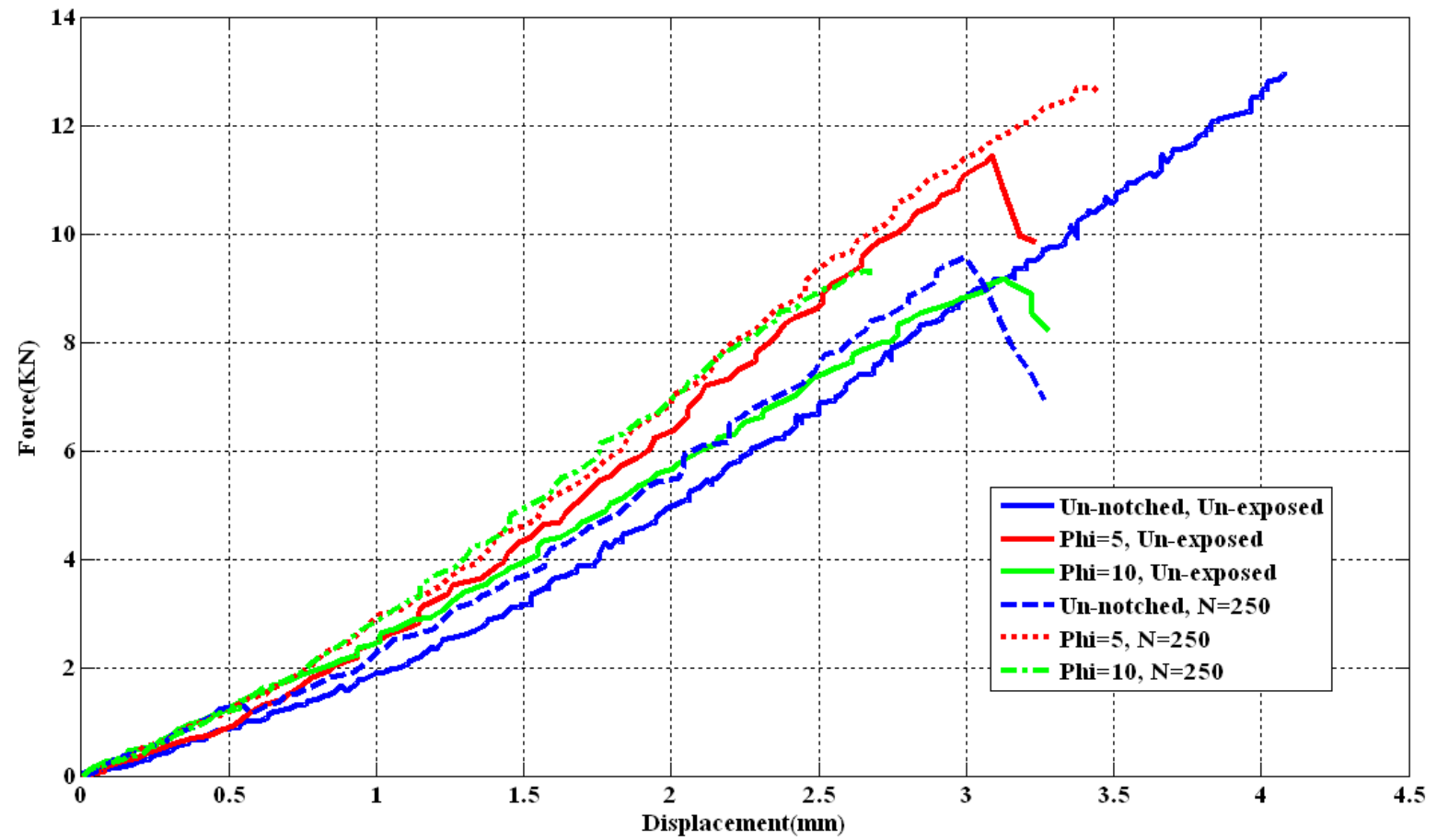

Fig. 4 Force-displacement curve of unnotched and open hole $\left[0_{2} / 90_{2}\right]_{\mathrm{S}}$ specimens after tensile test 

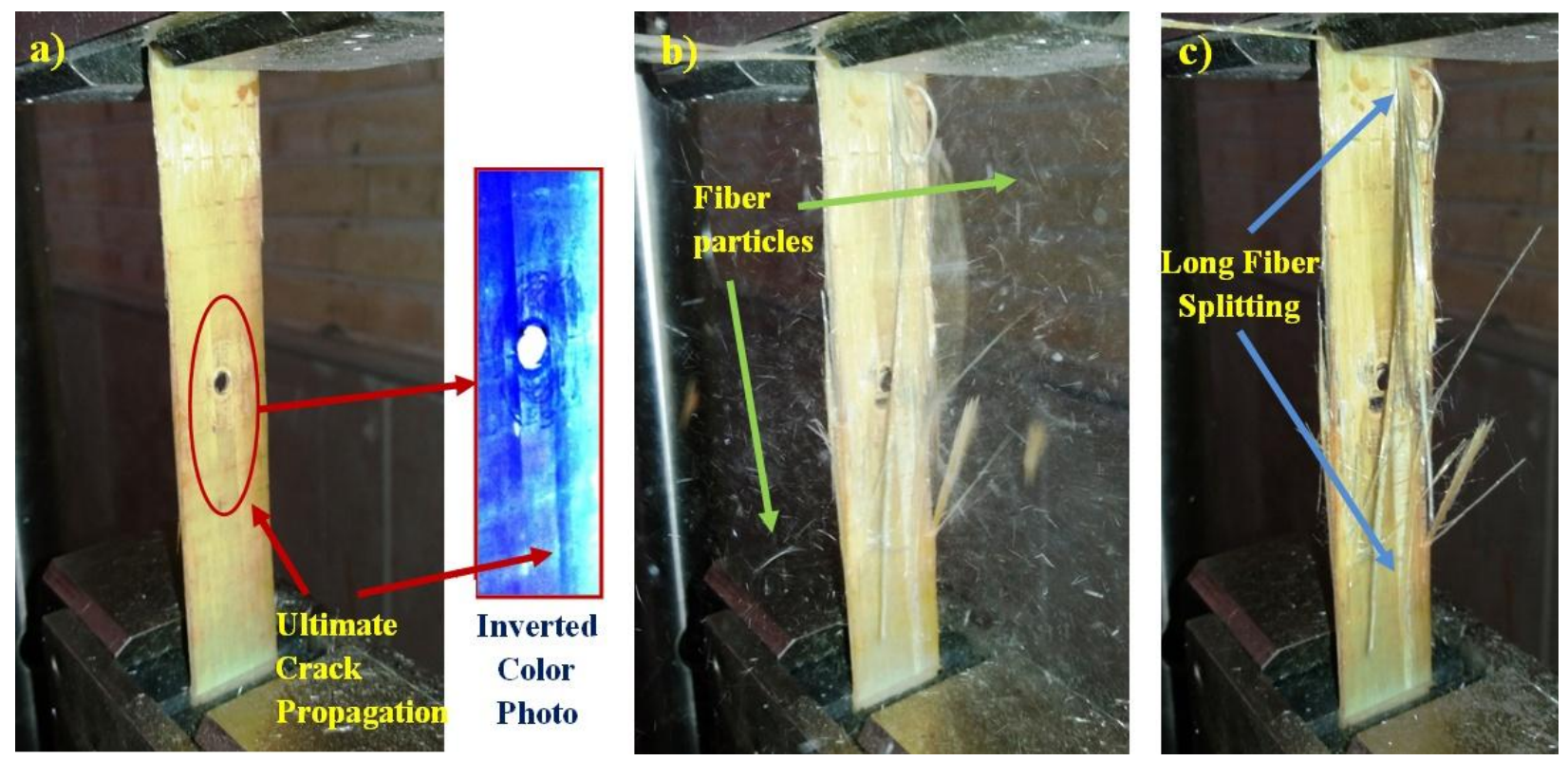

Fig. 5 Tensile test and failure of the $\left[0_{2} / 90_{2}\right]_{\mathrm{s}}$ specimens
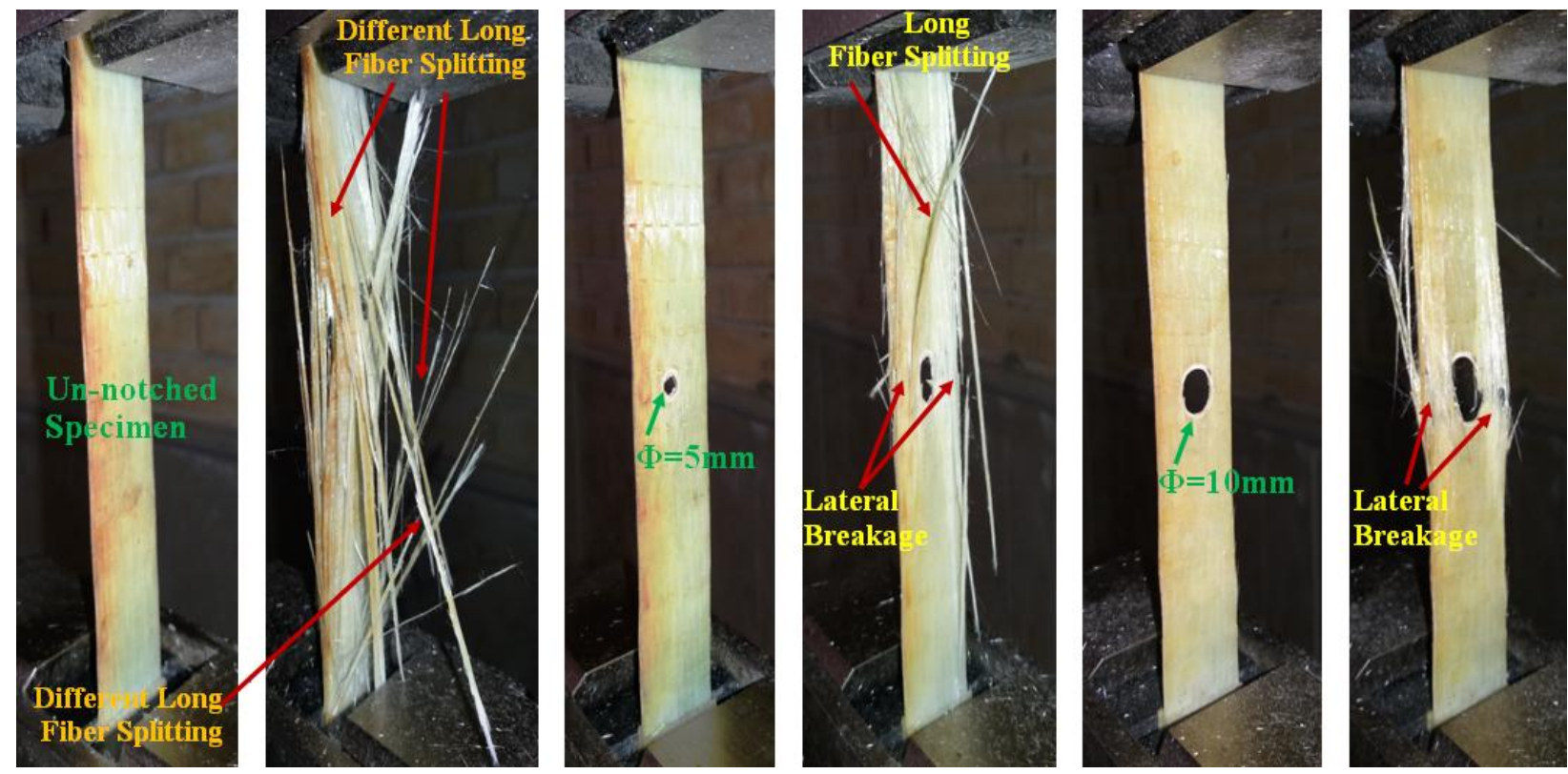

Fig. 6 Failure modes of un-notched and open-hole specimens 

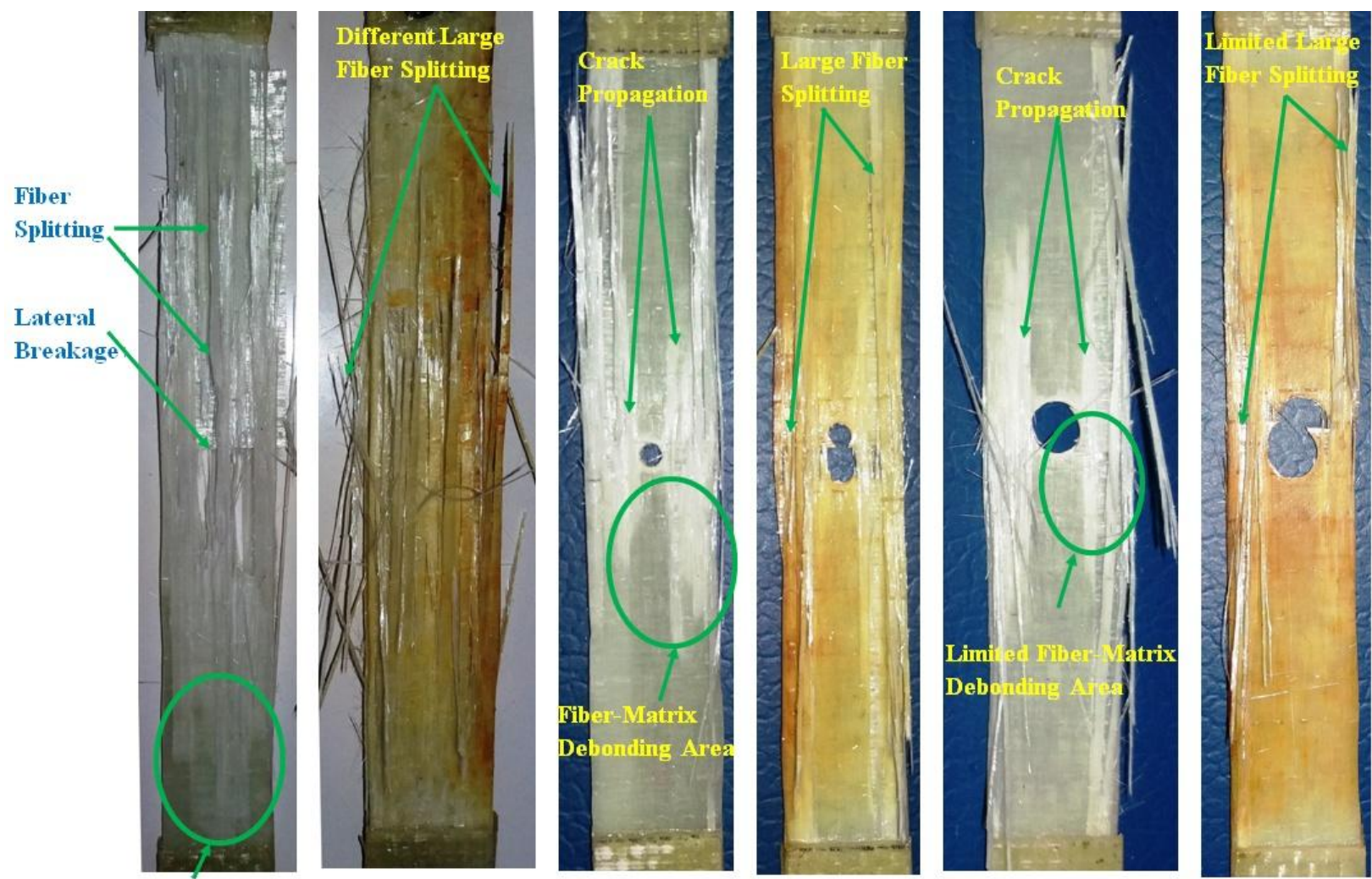

Wide Fiber-Matrix

Debonding Area

Fig. 7 Fracture behavior of unnotched and open hole specimens before and after thermal cycling test
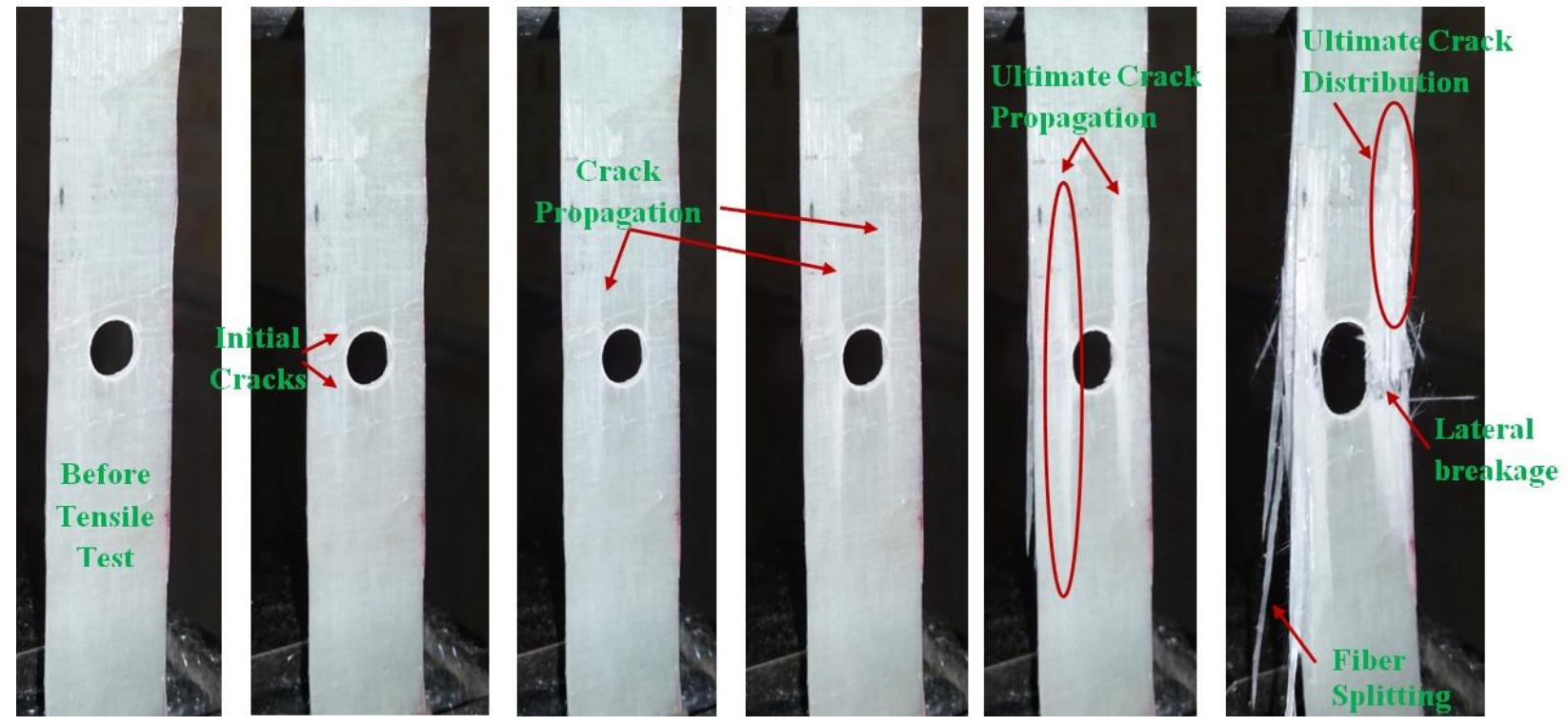

Fig. 8 Fracture behavior of unexposed open hole specimen during Tension test 

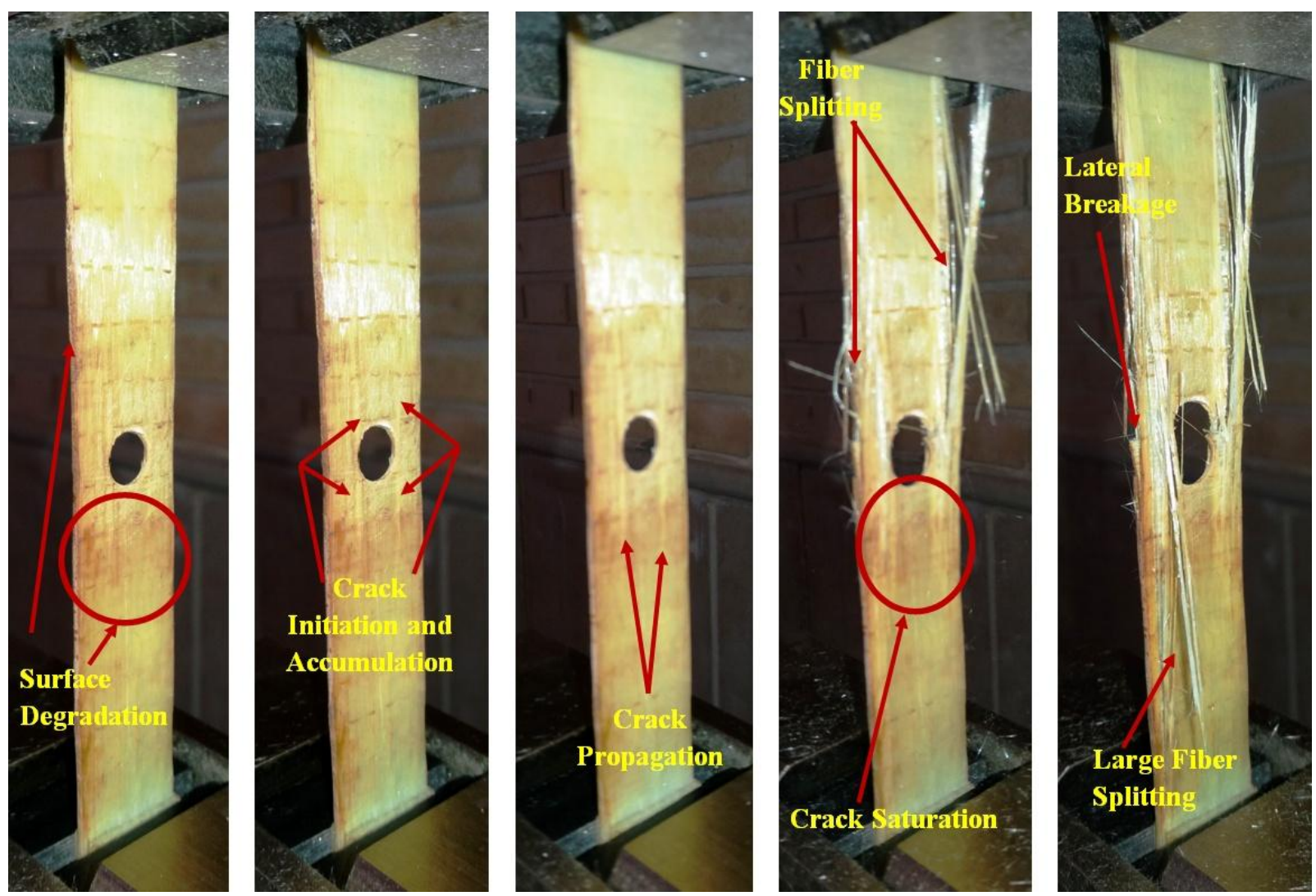

Fig. 9 Fracture behavior of open hole specimen after thermal cycling and during Tension test

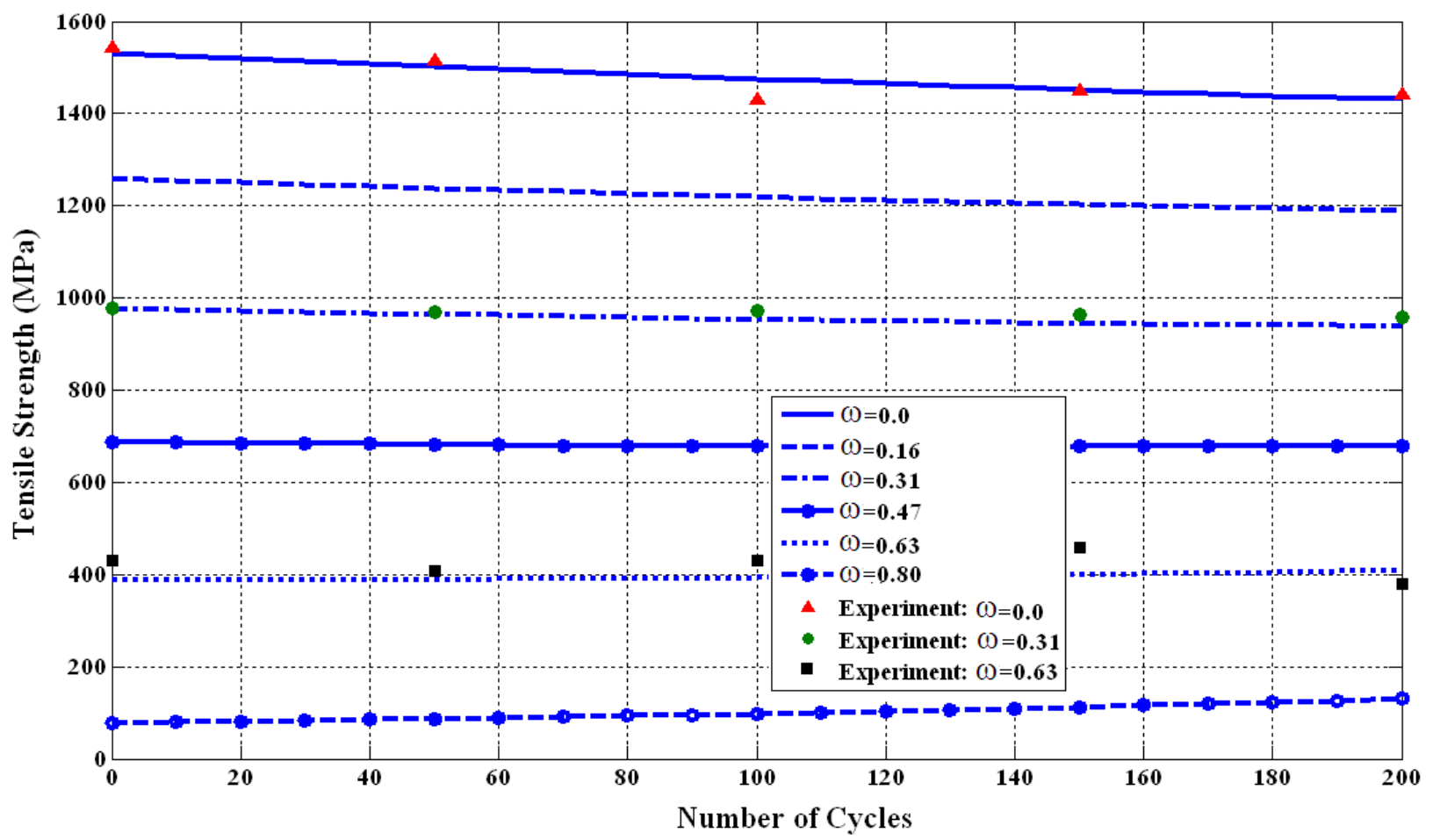

Fig. 10 Variation of the tensile strength as a function of the number of thermal cycles 


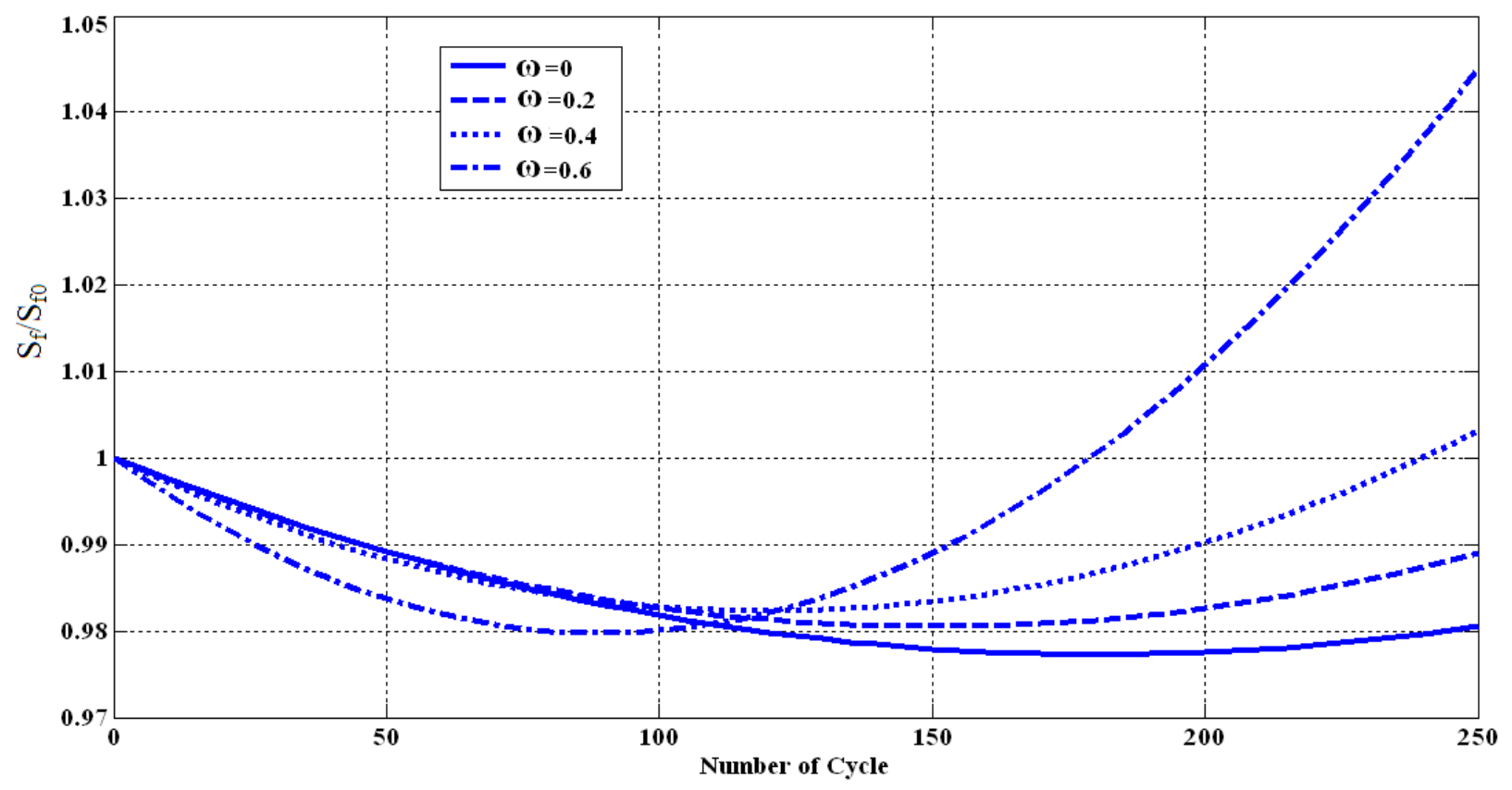

Fig. 11 Variation of dimensionless tensile strength as a function of thermal cycles

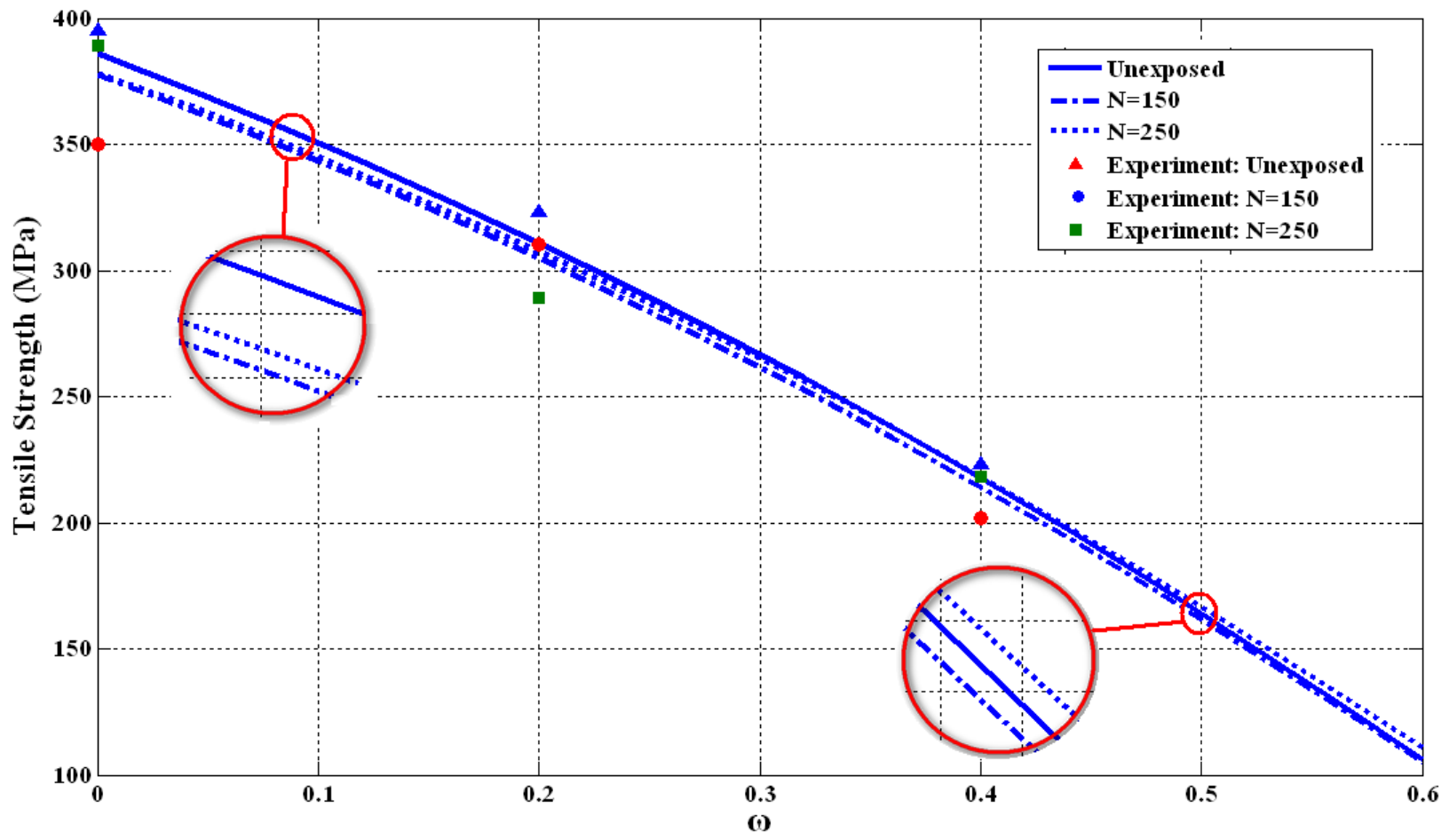

Fig. 12 Variation of the tensile strength as a function of the hole diameter to width ratio 
Table 1 Mechanical and physical properties of epoxy resin and glass fiber

\begin{tabular}{lccc}
\hline Material properties & Units & ML506 Epoxy & E-Glass \\
\hline Tensile modulus & $\mathrm{GPa}$ & 2.79 & 41 \\
Shear modulus & $\mathrm{GPa}$ & 15.24 & 15.24 \\
Poisson's ratio & - & 0.35 & 0.3 \\
Density & $\mathrm{g} / \mathrm{cm}^{3}$ & 1.11 & 2.48 \\
Coefficient of thermal expansion $(\mathrm{CTE})$ & $10^{-6} /{ }^{\circ} \mathrm{C}$ & 62 & 4.9 \\
\hline
\end{tabular}

Table 2 Average tensile strength of the specimens

\begin{tabular}{cccc}
\hline \multirow{2}{*}{ Number of thermal cycles } & \multicolumn{3}{c}{ Tensile strength (MPa) ( \pm SDV) } \\
\cline { 2 - 4 } & Unnotched & $\Phi=5 \mathrm{~mm}$ & $\Phi=10 \mathrm{~mm}$ \\
\hline 0 & $395.0(13.5)$ & $323.2(43.6)$ & $222.9(17.9)$ \\
50 & $377.9(18.7)$ & $314.8(8.4)$ & $219.4(12.3)$ \\
100 & $349.8(48.2)$ & $310.3(8.7)$ & $201.7(3.6)$ \\
150 & $398.4(72.3)$ & $317.2(2.9)$ & $216.0(13.1)$ \\
200 & $389.3(37.9)$ & $289.0(5.1)$ & $218.2(3.9)$ \\
250 & $373.7(61.5)$ & $305.3(13.2)$ & $217.9(16.2)$ \\
\hline
\end{tabular}

Table 3 The values of correlation coefficients $(0 \leq \mathrm{N} \leq 250,0 \leq \omega \leq 0.8)$

\begin{tabular}{cccccc}
\hline A & B & C & D & E & F \\
\hline 385.8 & -328 & -0.097 & 0.0818 & 9.225 & 0.000268 \\
\hline
\end{tabular}

